\title{
Is prophylactic lateral lymph node dissection needed for lower rectal cancer? A single-center retrospective study
}

\author{
Hiroka Kondo*, Shigeki Yamaguchi, Yasumitsu Hirano, Masayasu Aikawa, Hiroshi Sato, Kojun Okamoto,
} Shinichi Sakuramoto and Isamu Koyama

\begin{abstract}
Background: The effectiveness of prophylactic lateral lymph node dissection (LLND) in treating patients with lower rectal cancer remains controversial and has not been clearly established. Therefore, we aimed to retrospectively analyze the survival impact of prophylactic LLND in patients with lower rectal cancer.

Methods: Data of 301 patients with lower rectal cancer (tumor's lower edge on the anal side of the peritoneal reflexion) with clinical T3 disease and negative preoperative lateral lymph node metastasis, who underwent radical resection (RO) at our hospital between April 2007 and March 2017, were included in this study. Patients who received preoperative chemotherapy or radiotherapy were excluded. The relapse-free survival (RFS) and overall survival (OS) rates were compared between the dissection (prophylactic LLND, $n=37$ ) and non-dissection (no prophylactic LLND, $\mathrm{n}=264)$ groups.

Results: Significantly fewer men and younger patients were noted in the dissection group than in the non-dissection group. Post-surgery 3- and 5-year RFS rates were $69.6 \%$ and $66.8 \%$ in the dissection group and $75.1 \%$ and $72.5 \%$ in the non-dissection group, respectively (5-year post-surgery RFS, $p=0.58$ ). In the dissection and non-dissection groups, the 5-year OS rates were $86.5 \%$ and $79.7 \%$, respectively $(p=0.29)$, and the 5-year cancer-specific survival rates were $88.9 \%$ and $86.0 \%$, respectively $(p=0.29)$, with no significant differences. Lateral lymph node recurrence was observed in one (2.7\%) and 10 patients (3.8\%) in the dissection and non-dissection groups, respectively, and there was no significant difference between the groups.

Conclusions: In this study, the effectiveness of prophylactic LLND was limited in patients with > T3 lower rectal cancer with no evidence of preoperative lymph node metastasis. Prophylactic LLND may not be necessary if there is no preoperative lymph node metastasis, even if the invasion depth is T3 or higher.
\end{abstract}

Keywords: Rectal cancer, Lateral lymph node dissection, Lateral lymph node metastasis

*Correspondence: hkdaisy8890@yahoo.co.jp

Department of Gastroenterological Surgery, Saitama Medical

University International Medical Center, 1397-1 Yamane, Hidaka-shi,

Saitama 350-1298, Japan

\section{Background}

Rectal cancer is the tenth most deadly cancer, comprising $3.2 \%$ of all cancer-related deaths worldwide. The primary surgical modality for rectal cancers is proctectomy with lymph node dissection. According to the Japanese Colorectal Cancer Treatment Guidelines [1], lateral lymph node dissection (LLND) is recommended for rectal cancers in which the tumor's lower edge is present on the 
anal side of the peritoneal inversion and the wall depth is deeper than clinical T3. Although, the survival benefit of LLND in preoperatively or intraoperatively diagnosed negative lateral lymph node metastasis is limited, it is still weakly recommended because of its role in suppressing local recurrence [1]. Nevertheless, the significance of bilateral lymph node dissection in lower rectal cancers will remain controversial, owing to the prolonged operation time and increased incidence of postoperative complications, unless it truly improves patient prognosis.

From the inauguration of our hospital in 2007, rectal cancer surgery was primarily an open procedure, and prophylactic LLND was performed for lower rectal cancers deeper than clinical T3. However, since then, rectal cancer surgery has gradually shifted towards the laparoscopic approach. Moreover, simultaneous advances in diagnostic imaging have improved the sensitivity for detecting lymph node metastasis preoperatively. Therefore, after June 2011, LLND was omitted in cases without evidence of lateral lymphadenopathy before surgery. Despite the recommendations and relevant developments, the effectiveness of LLND in treating patients with lower rectal cancer is still a subject of debate and has not been clearly established. Thus, we retrospectively analyzed and compared the survival outcomes of patients with lower rectal cancer who were treated with or without prophylactic LLND.

\section{Methods}

This is a retrospective cohort study that focuses on the necessary of prophylactic LLND for rectum cancer. Data from a total of 301 patients with lower rectal cancer (lower tumor edge on the anal side of the peritoneal reflection) with clinical T3 disease, who were preoperatively diagnosed with negative lateral lymph node metastasis and underwent radical resection (R0) at our hospital from April 2007 to March 2017, were analyzed. Negative lateral lymph node metastasis was defined by the minor axis being shorter than $7.0 \mathrm{~mm}$ and a flat shape with even edges, as shown by computed tomography (CT) and magnetic resonance imaging. Patients who received preoperative chemotherapy or radiotherapy were excluded from the analysis. Also, if the surgeon accidentally found lymphadenopathy during the operation, such cases were excluded from the study. The patients were divided into two groups: patients who underwent prophylactic LLND (dissection group, $\mathrm{n}=37$ ) and those who did not undergo prophylactic LLND (non-dissection group, $n=264$ ).

The post-surgery 3- and 5-year relapse-free survival (RFS) and overall survival (OS) rates were compared between the two groups. In addition, the local recurrence rate and its site, treatment after recurrence of lateral lymph node metastasis, and the incidence of complications, such as postoperative anastomotic leakage and self-catheterization, were retrospectively compared and examined. Cancer-specific survival was also compared between the two groups.

All statistical analyses were performed using the SPSS software package (SPSS version 25, IBM Corp., Tokyo, Japan). Chi-squared and Mann-Whitney $U$ tests were performed to analyze the differences between the two groups. The cumulative cancer-specific survival rate was analyzed using the Kaplan-Meier method and log-rank tests. COX regression analysis was conducted to compare relapse-free survival (RFS) and overall survival (OS) rates. A $p$ value $<0.05$ was considered reflective of statistical significance.

\section{Results}

Patient characteristics for the dissection and non-dissection groups are shown in Table 1 . The male/female ratio and average age of the dissection $(\mathrm{n}=37)$ and nondissection groups $(\mathrm{n}=264)$ were $21 / 16$ and $197 / 67$ and $60.38 \pm 9.82$ and $64.87 \pm 11.52$ years, respectively. Significantly fewer men and younger patients were noted in the dissection group, which also had a significantly lower American Society of Anesthesiologists physical status (ASA-PS) than in the non-dissection group. There was no difference between the two groups in terms of preoperative carcinoembryonic antigen levels and body mass index, the presence or absence of a history of laparotomy, and the proportion of preoperative T3 and T4 diagnoses. The proportion of patients who were preoperatively diagnosed with positive central lymph node metastasis was $70.3 \%$ in the dissection group and $51.1 \%$ in the non-dissection group $(\mathrm{p}=0.03)$; however, there was no significant difference in the proportion of patients with pathological stage III disease between the groups $(\mathrm{p}=0.37)$.

Bilateral prophylactic LLND was a laparotomy-based procedure in all patients in the dissection group, and a significant difference was observed between the method of approach in the dissection (laparotomy) and non-dissection groups (laparoscopy). There was no significant difference between the two groups in terms of the proportion of surgical procedures involving anastomosis (low anterior resection or intersphincter rectal resection), histopathological examination results (well/moderately differentiated adenocarcinoma or other; T1-2 or T3-4 disease; and the presence or absence of lymphatic invasion, venous invasion, and nerve invasion), and enforcement rate of postoperative adjuvant chemotherapy.

There were two cases $(5.4 \%)$ with positive lateral lymph node metastasis in the dissection group (Table 1). The RFS rates, 3 and 5 years after surgery, were $69.6 \%$ and $66.8 \%$, respectively, in the dissection group, and $75.1 \%$ 
Table 1 Patient baseline characteristics

\begin{tabular}{|c|c|c|c|}
\hline Characteristic & $\begin{array}{l}\text { Dissection group } \\
(n=37)\end{array}$ & $\begin{array}{l}\text { Non-dissection group } \\
(n=264)\end{array}$ & $p$ value \\
\hline \multicolumn{4}{|l|}{ Sex } \\
\hline Male & $21(56.8)$ & $197(74.6)$ & \\
\hline Female & $16(43.2)$ & $67(25.4)$ & 0.02 \\
\hline \multirow[t]{2}{*}{ Age (years) } & $60.38 \pm 9.82$ & $64.87 \pm 11.52$ & 0.01 \\
\hline & $6.71 \pm 5.45$ & $21.18 \pm 132.85$ & 0.60 \\
\hline \multicolumn{4}{|l|}{ CEA (ng/mL) } \\
\hline$>5.0$ & $15(40.5)$ & $112(42.4)$ & \\
\hline \multirow[t]{2}{*}{$\leq 5.0$} & $22(59.5)$ & $152(57.6)$ & 0.83 \\
\hline & $22.19 \pm 3.44$ & $23.42 \pm 11.90$ & 0.37 \\
\hline \multicolumn{4}{|l|}{ BMI $\left(\mathrm{kg} / \mathrm{m}^{2}\right)$} \\
\hline$\geq 25$ & $7(18.9)$ & $64(24.2)$ & \\
\hline$<25$ & $30(81.1)$ & $200(75.8)$ & 0.48 \\
\hline \multicolumn{4}{|l|}{ History of laparotomy } \\
\hline Yes & $11(29.7)$ & 79 (29.9) & \\
\hline No & $26(70.3)$ & $185(70.1)$ & 0.98 \\
\hline \multicolumn{4}{|l|}{ ASA-PS } \\
\hline 1 & $27(73.0)$ & $101(38.3)$ & \\
\hline 2 & $9(24.3)$ & $128(48.5)$ & \\
\hline 3 & $1(2.7)$ & $35(13.3)$ & $<0.001$ \\
\hline \multicolumn{4}{|l|}{ Preoperative diagnosis } \\
\hline \multicolumn{4}{|l|}{ Depth } \\
\hline T3 & $32(86.5)$ & $219(83.0)$ & \\
\hline $\mathrm{T} 4$ & $5(13.5)$ & $45(17.0)$ & 0.59 \\
\hline \multicolumn{4}{|c|}{ Lymph node metastasis (central direction) } \\
\hline Yes & $26(70.3)$ & $135(51.1)$ & \\
\hline No & $11(29.7)$ & $129(48.9)$ & 0.03 \\
\hline \multicolumn{4}{|l|}{ Surgery } \\
\hline \multicolumn{4}{|l|}{ Approach } \\
\hline Laparotomy & $37(100.0)$ & $37(14.0)$ & \\
\hline Laparoscopy & $0(0.0)$ & $227(86.0)$ & $<0.001$ \\
\hline \multicolumn{4}{|c|}{ Including anastomosis } \\
\hline Yes & $28(75.7)$ & $221(83.7)$ & \\
\hline No & $9(24.3)$ & $43(16.3)$ & 0.23 \\
\hline \multicolumn{4}{|l|}{ Pathology } \\
\hline \multicolumn{4}{|l|}{ Histopathology } \\
\hline Well/moderate & $36(97.3)$ & $236(89.4)$ & \\
\hline Other & $1(2.7)$ & $28(10.6)$ & 0.10 \\
\hline \multicolumn{4}{|l|}{ Depth } \\
\hline $\mathrm{T} 1-2$ & $6(16.2)$ & $79(29.9)$ & \\
\hline $\mathrm{T} 3-4$ & $31(83.8)$ & $185(70.1)$ & 0.08 \\
\hline \multicolumn{4}{|c|}{ Lymph node metastasis } \\
\hline Central direction & $20(54.1)$ & $122(46.2)$ & 0.37 \\
\hline Lateral & 2 & - & \\
\hline \multicolumn{4}{|l|}{ Stage } \\
\hline I/II & $17(45.9)$ & $142(53.8)$ & \\
\hline III & $20(54.1)$ & $122(46.2)$ & 0.37 \\
\hline \multicolumn{4}{|l|}{ Lymphatic invasion } \\
\hline Yes & $11(29.7)$ & $78(29.8)$ & \\
\hline No & $26(70.3)$ & $184(70.2)$ & 0.996 \\
\hline
\end{tabular}


Table 1 (continued)

\begin{tabular}{lll}
\hline Characteristic & $\begin{array}{l}\text { Dissection group } \\
(\mathbf{n}=\mathbf{3 7})\end{array}$ & $\begin{array}{l}\text { Non-dissection group } \\
(\mathbf{n}=\mathbf{2 6 4 )}\end{array}$ \\
\hline $\begin{array}{l}\text { Venous invasion } \\
\text { Yes }\end{array}$ & $27(73.0)$ & $193(73.7)$ \\
No & $10(27.0)$ & $69(26.3)$ \\
Nerve invasion & $19(54.3)$ & $105(41.8)$ \\
Yes & $16(45.7)$ & $146(58.2)$ \\
No & & \\
Postoperative adjuvant therapy & $15(40.5)$ & $92(34.8)$ \\
Yes & $22(59.5)$ & $172(65.2)$ \\
No & & 0.16 \\
\hline
\end{tabular}

Data are presented as $\mathrm{n}(\%)$ or mean \pm standard deviation

ASA-PS American Society of Anesthesiologists physical status, BMI body mass index, CEA carcinoembryonic antigen

and $72.5 \%$, respectively, in the non-dissection group (RFS 5 years post-surgery, $\mathrm{p}=0.58$ ) (Fig. $1 \mathrm{a})$. The corresponding 5 -year OS rates were $86.5 \%$ and $79.7 \%(p=0.29)$, showing no significant difference (Fig. 1b). Furthermore, as for the background characteristics between the two groups, there were many young people in the dissection group and the ASA-PS tended to be good; hence, cancerspecific survival was also examined. The 5 -year cancerspecific survival rate was $88.9 \%$ in the dissection group and $86.0 \%$ in the non-dissection group $(\mathrm{p}=0.29)$, with no significant difference (Fig. 2). Cox regression analysis showed that male sex, high preoperative carcinoembryonic antigen levels, and pathological stage III disease had a significant effect on RFS. In addition to these factors, OS was affected by older age, open surgery, and non-adjuvant therapy. In either case (RFS or OS), the presence or absence of prophylactic LLND was not a significant factor (Table 2).

There was no significant difference in the overall recurrence rate $(\mathrm{p}=0.48)$ or the rate of pelvic recurrence between the two groups (Table 3). Of the pelvic recurrences, lateral lymph node recurrence was observed in one case $(2.7 \%)$ in the dissection group and in 10 cases $(3.8 \%)$ in the non-dissection group; however, no significant difference was observed $(\mathrm{p}=0.88)$. Of the seven patients in the non-dissection group who experienced initial recurrence as metastatic lateral lymph node involvement, lateral dissection was performed in five patients, and RFS was achieved in four patients. Moreover, three cases of distant lateral lymph node
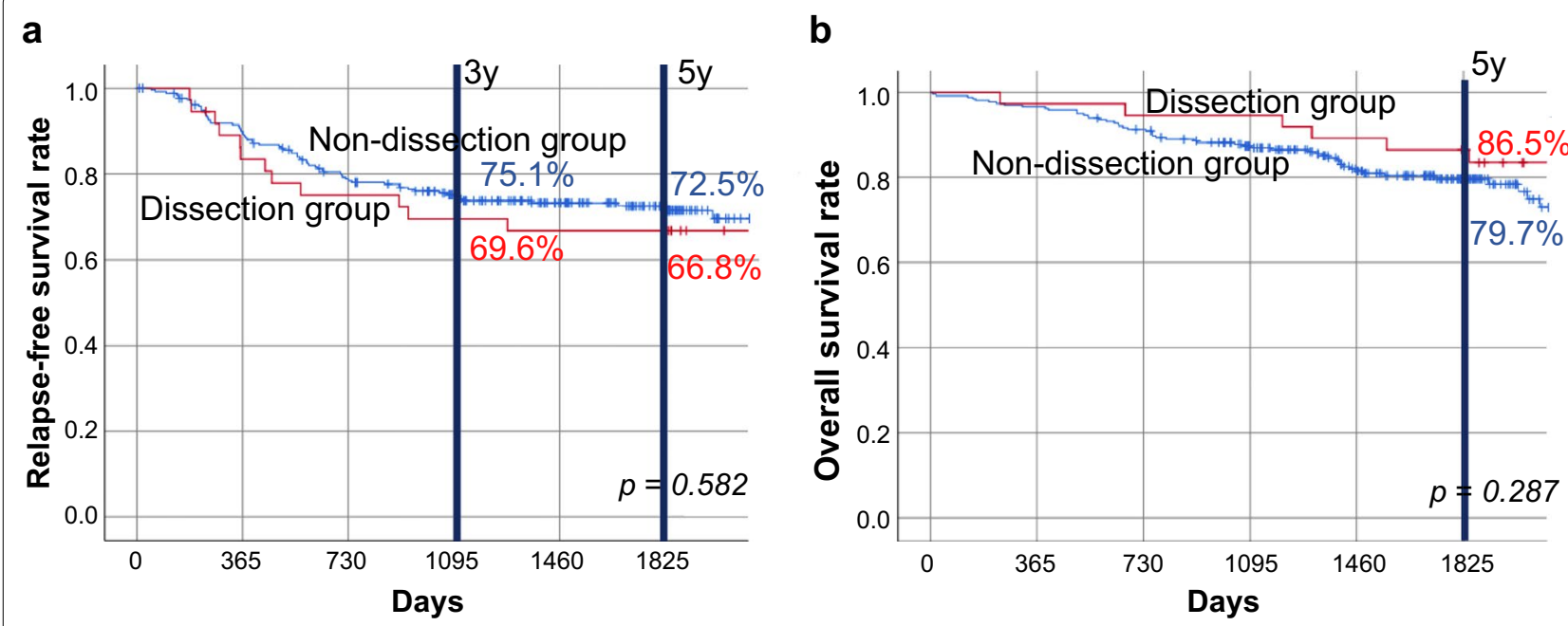

Fig. 1 Relapse-free and overall survival. a Relapse-free survival. Kaplan-Meier curves of patients in the dissection group (red) and the non-dissection group (blue) indicating relapse-free survival rates. b Overall survival. Kaplan-Meier curves of patients in the dissection group (red) and the non-dissection group (blue) indicating overall survival rates 


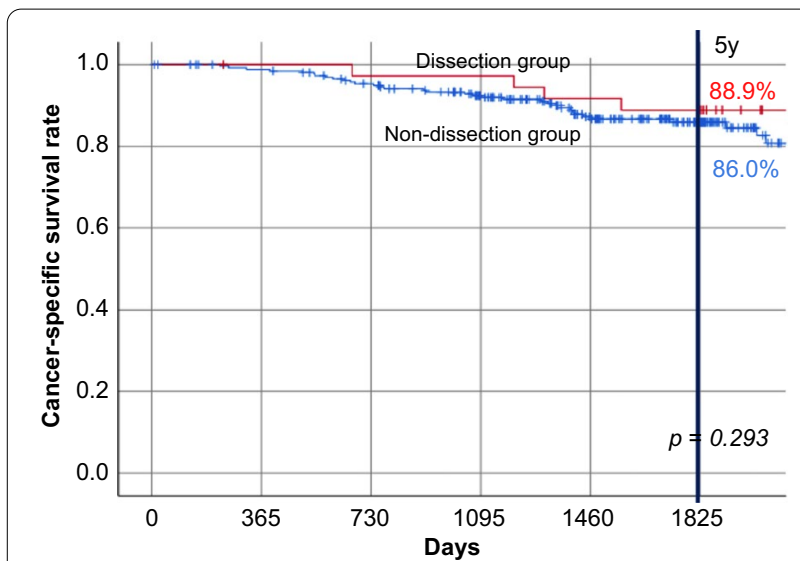

Fig. 2 Cancer-specific survival. Kaplan-Meier curves of patients in the dissection group (red) and the non-dissection group (blue) indicating cancer-specific survival rates

metastasis were noted, and none of them were treated by resection (Fig. 3). In the short-term, the mean operation time and blood loss were $317.92 \pm 70.06 \mathrm{~min}$ and $467.68 \pm 407.88 \mathrm{~mL}$, respectively, in the dissection group and $262.03 \pm 72.38 \mathrm{~min}$ and $79.79 \pm 163.41 \mathrm{~mL}$, respectively, in the non-dissection group. That is, the duration of surgery was significantly shorter, and the volume of bleeding was lower in the non-dissection group (Table 4). There was no significant difference in postoperative complications of Clavien-Dindo classification grade II or higher in six patients $(16.2 \%)$ in the dissection group and 73 patients $(27.7 \%)$ in the non-dissection group. Among postoperative complications, the incidence of anastomotic leakage was $14.3 \%$ in the dissection group and $14.0 \%$ in the non-dissection group. There was no significant difference in dysuria requiring self-catheterization between the dissection and non-dissection groups, respectively. The postoperative hospital stay was not significantly different between the two groups (Table 4).

\section{Discussion}

In this study, we retrospectively evaluated the survival impact of prophylactic LLND in patients with lower rectal cancer. We found that the OS and RFS rates were not significantly different between the dissection and non-dissection groups. Therefore, the effectiveness of prophylactic LLND was found to be limited in patients with rectal cancer $>\mathrm{T} 3$ with no evidence of preoperative lymph node metastasis.

In Japan, a randomized controlled phase III trial (JCOG0212: ClinicalTrials.gov NCT00190541) [2] was conducted to evaluate the non-inferiority of mesorectal excision (ME) alone versus LLND plus ME in patients with clinical stage II/III rectal cancer without lateral

Table 3 Recurrence rates of all patients

\begin{tabular}{lccc}
\hline Variable & $\begin{array}{l}\text { Dissection group } \\
(\mathbf{n}=\mathbf{3 7})\end{array}$ & $\begin{array}{l}\text { Non- } \\
\text { dissection } \\
\text { group } \\
(\mathbf{n = 2 6 4 )}\end{array}$ & p value \\
& & $71(26.9)$ & \\
\hline $\begin{array}{l}\text { All recurrence, n (\%) } \\
\text { Yes }\end{array}$ & $12(32.4)$ & $193(73.1)$ & 0.48 \\
No & $25(67.6)$ & $22(8.3)$ & \\
Pelvic recurrence, n (\%) & & $241(91.3)$ & \\
Yes & $3(8.1)$ & $1(0.4)$ & 0.93 \\
No & $34(91.9)$ & & \\
Unknown & $0(0.0)$ & $10(3.8)$ & \\
Lateral lymph node & & $254(96.2)$ & 0.88 \\
recurrence, n (\%) & $1(2.7)$ & & \\
Yes & $36(97.3)$ & & \\
No &
\end{tabular}

Data are presented as $\mathrm{n}(\%)$ " below the table

Table 2 Cox regression analysis of patient characteristics

\begin{tabular}{|c|c|c|c|c|c|c|}
\hline \multirow[t]{2}{*}{ Characteristic } & \multicolumn{3}{|c|}{ Relapse-free survival } & \multicolumn{3}{|c|}{ Overall survival } \\
\hline & HR & $95 \% \mathrm{Cl}$ & p value & HR & $95 \% \mathrm{Cl}$ & p value \\
\hline Male vs. female & 0.561 & $0.323-0.973$ & 0.04 & 0.474 & $0.243-0.927$ & 0.03 \\
\hline Age (years) & 0.992 & $0.971-1.013$ & 0.44 & 1.036 & $1.008-1.065$ & 0.01 \\
\hline CEA level (> $5.0 \mathrm{vs.} \leq 5.0 \mathrm{ng} / \mathrm{mL})$ & 0.485 & $0.309-0.762$ & 0.002 & 0.420 & $0.249-0.709$ & 0.001 \\
\hline Surgery (laparoscopy vs. open) & 1.331 & $0.695-2.549$ & 0.39 & 2.080 & $1.119-3.866$ & 0.02 \\
\hline LLND (yes vs. no) & 1.072 & $0.464-2.476$ & 0.87 & 2.121 & $0.898-5.013$ & 0.09 \\
\hline Anastomotic leakage (yes vs. no) & 1.055 & $0.530-2.098$ & 0.88 & 1.191 & $0.518-2.740$ & 0.68 \\
\hline Histopathology (well/moderate vs. other) & 0.846 & $0.385-1.861$ & 0.68 & 0.470 & $0.185-1.191$ & 0.11 \\
\hline Depth (pT3-4 vs. pT1-2) & 0.681 & $0.380-1.220$ & 0.20 & 0.557 & $0.276-1.124$ & 0.10 \\
\hline pStage (3 vs. 1-2) & 0.266 & $0.140-0.505$ & $<0.001$ & 0.32 & $0.169-0.590$ & $<0.001$ \\
\hline Adjuvant chemotherapy (yes vs. no) & 1.219 & $0.668-2.227$ & 0.52 & 2.23 & $1.167-4.272$ & 0.02 \\
\hline
\end{tabular}

CEA carcinoembryonic antigen, $C l$ confidence interval, $H R$ hazard ratio, LLND lateral lymph node dissection 


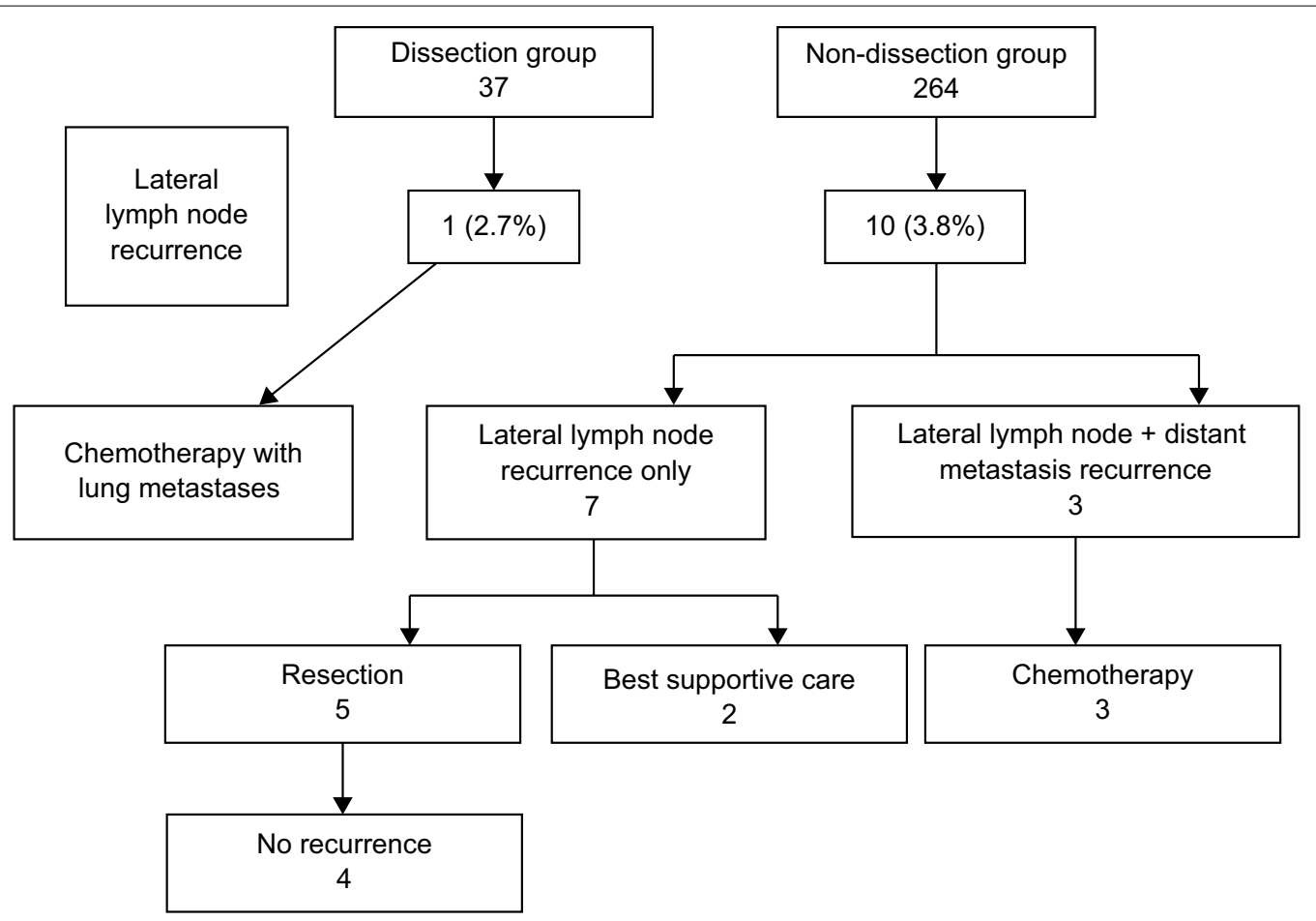

Fig. 3 Treatment course after lateral lymph node metastasis recurrence

Table 4 Short-term postoperative outcomes

\begin{tabular}{lll}
\hline Variable & $\begin{array}{l}\text { Dissection group } \\
(\mathbf{n = 3 7 )}\end{array}$ & $\begin{array}{l}\text { Non-dissection group } \\
(\mathbf{n = 2 6 4 )}\end{array}$ \\
\hline Operation time (min) & $317.92 \pm 70.06$ & $262.03 \pm 72.38$ \\
Blood loss (mL) & $467.68 \pm 407.88$ & $79.79 \pm 163.41$ \\
Clavien-Dindo classification, $\mathrm{n}(\%)$ & & \\
Grade V & $0(0.0)$ & $1(0.4)$ \\
Grade IV & $0(0.0)$ & $0(0.0)$ \\
Grade III & $4(10.8)$ & $37(14.0)$ \\
Grade II & $2(5.4)$ & $35(13.3)$ \\
Grade I & $8(21.6)$ & $28(10.6)$ \\
Grade 0 & $23(62.2)$ & $163(61.7)$ \\
Anastomotic leakage, $n$ (\%) & & $31(14.0)$ \\
Yes & $4(14.3)$ & $190(86.0)$ \\
No & $24(85.7)$ & $8(3.0)$ \\
Clean intermittent catheterization, $n(\%)$ & & $256(97.0)$ \\
Yes & $0(0.0)$ & $14.82 \pm 16.07$ \\
No & $37(100.0)$ & 0.26 \\
Postoperative hospital stay (days) & $14.84 \pm 9.42$ & 0.58 \\
\hline
\end{tabular}

Data are presented as the mean \pm standard deviation unless otherwise noted

lymphadenopathy. However, the study did not achieve its objective of demonstrating non-superiority. The endpoint, RFS, was similar between the two groups; however, patients who underwent ME alone had a significantly higher rate of local recurrence than did those who underwent LLND plus ME [2]. A subsequent study [3] has shown that LLND is more effective in clinical stage III patients than in clinical stage II patients. Currently, 
according to the Japanese Colorectal Cancer Treatment Guidelines, LLND is strongly recommended for lower rectal cancer deeper than T3 with lymphadenopathy, and weakly recommended for cases without [1]. In contrast, a study [4] has reported that prophylactic LLND does not contribute to the recurrence or survival rates, which is consistent with the results of our study. In other words, the postoperative survival and recurrence rates of patients with rectal cancer who have a preoperative diagnosis of negative lateral lymph node metastasis were comparable between those receiving and those not receiving prophylactic LLND. In our study, although the RFS rate was slightly lower in the dissection group than in the non-dissection group, the OS rate was slightly higher in the former. Since the average age of the dissection group was significantly younger than that of the non-dissection group, treatment after recurrence may have been adequate in many cases. In addition, when cancer-specific survival was examined to exclude the effects of other diseases in the elderly group in which dissection was omitted, the difference between the two groups almost disappeared. There was no difference in the local recurrence rate between the two groups. There was no significant difference in the lateral lymph node recurrence rate; however, the rate was slightly higher in the group in which dissection was omitted. These results suggest that LLND does not eliminate lateral lymph node recurrence, and that lateral lymph node recurrence in the non-dissection group is often curable.

There are several reports showing that LLND affects urination and sexual dysfunction [5]. This study compared voiding dysfunction with and without self-catheterization. The incidence of voiding dysfunction was very low in both groups, and no cases required self-catheterization after LLND. It has been reported that the degree of urination and sexual dysfunction can be reduced by preserving the autonomic nerve [6-9], and that there is no difference in the frequency of urination and sexual dysfunction with or without LLND [10, 11]. The risk of dysuria may be considerably low with current nerve preservation and LLND techniques, but the occurrence of dysuria in the JCOG0212 trial was not related to the presence or absence of LLND, and the volume of bleeding was a risk factor [12]. As for male sexual dysfunction, LLND did not have an effect, and age was identified as a risk factor [11]. We can infer that LLND does not invariably cause complications, but it may be associated with an increased risk of bleeding.

Additionally, several risk factors for positive lateral lymph nodes have been reported previously. Preoperative risk factors include age, sex, tumor location, depth of invasion, central nodal involvement, and lateral node size [13-23]. Studies on the size of lymph nodes in terms of the major or minor axis and various lengths have been conducted; however, in this study, lateral lymph nodes with minor axes shorter than $7.0 \mathrm{~mm}$, as identified using $\mathrm{CT}$ and magnetic resonance imaging, constituted the criterion for negative metastasis, and many institutions in Japan now use this criterion. Despite implementing this criterion in two cases, which accounted for $5.4 \%$ of the dissection group, lymph node metastasis was histologically confirmed in the lateral lymph node, which points to the need for further evaluation of the optimum imaging modality and lymph node size and shape criteria for identifying lateral lymph node metastasis. Tumor marker monitoring every 3 months and $\mathrm{CT}$ examination every 6 months were performed in this study. In the 10 patients with lateral lymph node metastasis who did not undergo prophylactic LLND, the mean time to recurrence was 635.8 (102-1661) days. Since the time to recurrence was quite long, these results emphasize the importance of not neglecting surveillance until 5 years after surgery.

Finally, in this study, anastomotic leakage did not affect RFS and OS. Some previous reports, like our study results, indicate that there is no association between anastomotic leakage and local recurrence [24, 25], while others point to an increase in the local recurrence rate in patients with anastomotic leakage [26, 27]. As for the risk factors for anastomotic leakage, "being a man" has been reported [28-30], and technical factors are fully considered as causes of anastomotic leakage and local recurrence. We practice total mesorectal excision $[31,32]$ with the utmost care not to destroy the fascia propria of rectum, and we believe that this is one of the factors that did not create an association between anastomotic leakage and recurrence rate and survival rate.

This study has several limitations. First, this was a single-institution retrospective analysis. Second, biases were introduced due to the lack of randomization or propensity scoring. Third, all the dissection group cases were open, whereas many of the non-dissection group cases were laparoscopic; moreover, the dissection group was considerably older than the non-dissection group. In the future, more accurate methods for extracting cases that would benefit from prophylactic LLND and the administration of preoperative radiotherapy are warranted. Furthermore, we need to be cautious about performing unnecessary prophylactic LLND procedures that could deteriorate patients' postoperative quality of life.

\section{Conclusion}

In conclusion, this study demonstrated that the effectiveness of prophylactic LLND was limited in patients with $>$ T3 rectal cancers with no evidence of preoperative lymph node metastasis. Prophylactic LLND may not be 
necessary if there is no preoperative lymph node metastasis, even if the invasion depth is T3 or higher.

\author{
Abbreviations \\ ASA-PS: American Society of Anesthesiologists physical status; CT: Computed \\ tomography; LLND: Lateral lymph node dissection; ME: Mesorectal excision; \\ OS: Overall survival; RFS: Relapse-free survival.
}

\section{Acknowledgements}

We would like to thank Editage (www.editage.com) for their writing support.

\section{Authors' contributions}

HK drafted this manuscript under the supervision of SY. YH, MA and SY contributed to the conception or design of the work. HS, KO, SS, and IK contributed to the acquisition, analysis, or interpretation of data. All authors were tasked with content review. All authors have read and approved the final manuscript.

\section{Funding}

This research did not receive any specific Grant from funding agencies in the public, commercial, or not-for-profit sectors.

\section{Availability of data and materials}

The datasets generated and/or analyzed during the current study are not publicly available due to patient privacy and security of electronic medical information but are available (anonymized) from the corresponding author on reasonable request.

\section{Declarations}

\section{Ethics approval and consent to participate}

The study design was approved by the Ethics Committee of Saitama Medical University International Medical Center (approval number: 20-029). All participants provided written informed consent. The study was performed in accordance with the ethical standards of the Declaration of Helsinki (1964) and its subsequent amendments.

\section{Consent for publication}

Not applicable.

\section{Competing interests}

The authors declare that they have no competing interests.

Received: 28 March 2021 Accepted: 18 May 2021

Published online: 26 May 2021

\section{References}

1. Hashiguchi Y, Muro K, Saito Y, Ito Y, Ajioka Y, Hamaguchi T, et al. Japanese Society for Cancer of the Colon and Rectum (JSCCR) guidelines 2019 for the treatment of colorectal cancer. Int J Clin Oncol. 2020;25:1-42.

2. Fujita S, Mizusawa J, Kanemitsu Y, Ito M, Kinugasa Y, Komori K, et al. Mesorectal excision with or without lateral lymph node dissection for clinical stage II/III lower rectal cancer (JCOG0212): a multicenter, randomized controlled, noninferiority trial. Ann Surg. 2017;266:201-7.

3. Tsukamoto S, Fujita S, Ota M, Mizusawa J, Shida D, Kanemitsu Y, et al. Long-term follow-up of the randomized trial of mesorectal excision with or without lateral lymph node dissection in rectal cancer (JCOG0212). Br J Surg. 2020;107:586-94.

4. Cheng H, Deng Z, Wang ZJ, Zhang W, Su JT. Lateral lymph node dissection with radical surgery versus single radical surgery for rectal cancer: a meta-analysis. Asian Pac J Cancer Prev. 2011;12:2517-21.

5. Nishizawa Y, Ito M, Saito N, Suzuki T, Sugito M, Tanaka T. Male sexual dysfunction after rectal cancer surgery. Int J Colorectal Dis. 2011;26:1541-8.

6. Akasu T, Sugihara K, Moriya Y. Male urinary and sexual functions after mesorectal excision alone or in combination with extended lateral pelvic lymph node dissection for rectal cancer. Ann Surg Oncol. 2009;16:2779-86.

7. Dong XS, Xu HT, Li ZG, Liu F. Effect of lateral lymph nodes dissection and autonomic nerve preservation in anterior resection for rectal cancer: 124 cases review. Xing J Zhonghua Wai Ke Za Zhi. 2007;45:1164-6.

8. Kyo K, Sameshima S, Takahashi M, Furugori T, Sawada T. Impact of autonomic nerve preservation and lateral node dissection on male urogenital function after total mesorectal excision for lower rectal cancer. World J Surg. 2006;30:1014-9.

9. Maeda K, Maruta M, Utsumi T, Sato H, Toyama K, Matsuoka H. Bladder and male sexual functions after autonomic nerve-sparing TME with or without lateral node dissection for rectal cancer. Tech Coloproctol. 2003;7:29-33.

10. Koyama M, Okada K, Kitamura K, Matsumura T, Totsuka E, Karikomi K, et al. Assessment of long-term sexual function after radical resection for lower rectal cancer. Gan To Kagaku Ryoho. 2017;44:1500-2.

11. Saito S, Fujita S, Mizusawa J, Kanemitsu Y, Saito N, Kinugasa Y, et al. Male sexual dysfunction after rectal cancer surgery: results of a randomized trial comparing mesorectal excision with and without lateral lymph node dissection for patients with lower rectal cancer: Japan Clinical Oncology Group Study JCOG0212. Eur J Surg Oncol. 2016;42:1851-8.

12. Ito M, Kobayashi A, Fujita S, Mizusawa J, Kanemitsu Y, Kinugasa Y, et al. Urinary dysfunction after rectal cancer surgery: results from a randomized trial comparing mesorectal excision with and without lateral lymph node dissection for clinical stage II or III lower rectal cancer (Japan Clinical Oncology Group Study, JCOG0212). Eur J Surg Oncol. 2018;44:463-8.

13. Ueno M, Oya M, Azekura K, Yamaguchi T, Muto T. Incidence and prognostic significance of lateral lymph node metastasis in patients with advanced low rectal cancer. Br J Surg. 2005;92:756-63.

14. Sugihara K, Kobayashi H, Kato T, Mori T, Mochizuki H, Kameoka S, et al. Indication and benefit of pelvic sidewall dissection for rectal cancer. Dis Colon Rectum. 2006;49:1663-72.

15. Kobayashi H, Mochizuki H, Kato T, Mori T, Kameoka S, Shirouzu K, et al. Outcomes of surgery alone for lower rectal cancer with and without pelvic sidewall dissection. Dis Colon Rectum. 2009;52:567-76.

16. Fujita S, Yamamoto S, Akasu T, Moriya Y. Risk factors of lateral pelvic lymph node metastasis in advanced rectal cancer. Int J Colorectal Dis. 2009:24:1085-90.

17. Tan KY, Yamamoto S, Fujita S, Akasu T, Moriya Y. Improving prediction of lateral node spread in low rectal cancers-multivariate analysis of clinicopathological factors in 1046 cases. Langenbecks Arch Surg. 2010;395:545-9.

18. Akiyoshi T, Watanabe T, Miyata S, Kotake K, Muto T, Sugihara K, et al. Results of a Japanese nationwide multi-institutional study on lateral pelvic lymph node metastasis in low rectal cancer: is it regional or distant disease? Ann Surg. 2012;255:1129-34.

19. Akiyoshi T, Matsueda K, Hiratsuka M, Unno T, Nagata J, Nagasaki T, et al. Indications for lateral pelvic lymph node dissection based on magnetic resonance imaging before and after preoperative chemoradiotherapy in patients with advanced low-rectal cancer. Ann Surg Oncol. 2015;22(Suppl 3):S614-20.

20. Kinugasa T, Akagi Y, Ochi T, Ishibashi Y, Tanaka N, Oka Y, et al. Lateral lymph-node dissection for rectal cancer: meta-analysis of all 944 cases undergoing surgery during 1975-2004. Anticancer Res. 2013;33:2921-7.

21. Nagayoshi K, Ueki T, Manabe T, Moriyama T, Yanai K, Oda Y, et al. Laparoscopic lateral pelvic lymph node dissection is achievable and offers advantages as a minimally invasive surgery over the open approach. Surg Endosc. 2016;30:1938-47.

22. Ogawa S, Hida J, Ike H, Kinugasa T, Ota M, Shinto E, et al. The important risk factor for lateral pelvic lymph node metastasis of lower rectal cancer is node-positive status on magnetic resonance imaging: study of the Lymph Node Committee of Japanese Society for Cancer of the Colon and Rectum. Int J Colorectal Dis. 2016;31:1719-28.

23. Komori K, Fujita S, Mizusawa J, Kanemitsu Y, Ito M, Shiomi A, et al. Predictive factors of pathological lateral pelvic lymph node metastasis in patients without clinical lateral pelvic lymph node metastasis (clinical stage II/III): the analysis of data from the clinical trial (JCOG0212). Eur J Surg Oncol. 2019;45:336-40.

24. Eriksen MT, Wibe A, Norstein J, Haffner J, Wiig JN. Anastomotic leakage following routine mesorectal excision for rectal cancer in a national cohort of patients. Colorectal Dis. 2005;7:51-7. 
25. Karanjia ND, Corder AP, Bearn P, Heald RJ. Leakage from stapled low anastomosis after total mesorectal excision for carcinoma of the rectum. Br J Surg. 1994;81:1224-6.

26. Petersen S, Freitag M, Hellmich G, Ludwig K. Anastomotic leakage: impact on local recurrence and survival in surgery of colorectal cancer. Int J Colorectal Dis. 1998;13:160-3.

27. Bell SW, Walker KG, Rickard MJ, Sinclair G, Dent OF, Chapuis PH, et al. Anastomotic leakage after curative anterior resection results in a higher prevalence of local recurrence. Br J Surg. 2003;90:1261-6.

28. Marusch F, Koch A, Schmidt U, Wenisch H, Ernst M, Manger T, et al. Early postoperative results of surgery for rectal carcinoma as a function of the distance of the tumor from the anal verge: results of a multicenter prospective evaluation. Langenbecks Arch Surg. 2002;387:94-100.

29. Law WI, Chu KW, Ho JW, Chan CW. Risk factors for anastomotic leakage after low anterior resection with total mesorectal excision. Am J Surg. 2000;179:92-6.
30. Rullier E, Laurent C, Garrelon JL, Michel P, Saric J, Parneix M. Risk factors for anastomotic leakage after resection of rectal cancer. Br J Surg. 1998;85:355-8.

31. Heald RJ, Husband EM, Ryall RD. The mesorectum in rectal cancer surgery-the clue to pelvic recurrence? Br J Surg. 1982;69:613-6.

32. Enker WE, Thaler HT, Cranor ML, Polyak T. Total mesorectal excision in the operative treatment of carcinoma of the rectum. J Am Coll Surg. 1995; 181:335-46.

\section{Publisher's Note}

Springer Nature remains neutral with regard to jurisdictional claims in published maps and institutional affiliations.
Ready to submit your research? Choose BMC and benefit from:

- fast, convenient online submission

- thorough peer review by experienced researchers in your field

- rapid publication on acceptance

- support for research data, including large and complex data types

- gold Open Access which fosters wider collaboration and increased citations

- maximum visibility for your research: over $100 \mathrm{M}$ website views per year

At BMC, research is always in progress.

Learn more biomedcentral.com/submissions 